\title{
La tapia en España. Técnicas actuales y ejemplos
}

\section{Rammed earth in Spain: current techniques and examples}

\author{
F. Font $^{(*)}$, P. Hidalgo(**)
}

\section{RESUMEN}

La tapia, esa milenaria técnica de construir muros consistente en apisonar tierra húmeda dentro de un molde de madera llamado tapial, ha sido profusamente empleada en la Península lbérica desde muy antiguo, tanto en la arquitectura monumental como popular, hasta que a principios del siglo pasado entró en franca decadencia, llegando prácticamente a desaparecer unas décadas después.

En Europa, tras la crisis energética de finales de los años setenta, un sector de la población tomó conciencia de la escasez y del agotamiento de los recursos naturales del planeta. Muchos arquitectos y distintos agentes vinculados al sector de la construcción y la investigación se propusieron rescatar materiales y antiguas técnicas constructivas, en un intento de conciliar las exigencias de la edificación actual con los parámetros de la arquitectura bioclimática.

En España, aunque más tardíamente, también ha surgido con determinación este movimiento y en los últimos 20 años han proliferado viviendas y todo tipo de edificaciones construidas a base de tierra.

El tradicional tapial y el apisonado manual conviven actualmente con los encofrados procedentes de la industria del hormigón, pero la modernización de la técnica se va imponiendo paulatinamente.

La diversidad de tipologías de edificaciones de tapia levantadas en los últimos años en España es, como puede verse en este trabajo, significativa. En nuestra opinión esto viene a corroborar que esta milenaria técnica constructiva regresa de un injustificado olvido y se reafirma en un esperanzador futuro.

$113-97$

Palabras clave: tapia, técnicas actuales, ejemplos, tierra, construcción.

\section{SUMMARY}

Rammed earth is a thousand-year old technique for building walls, and consists of compacting damp earth inside a wooden mould known as a formwork. This method was widely used across the Iberian Peninsula for centuries, in both monumental and vernacular architecture, until it began to decline at the beginning of the last century, and practically disappeared just a few decades later.

In Europe, the energy crisis of the late 1970s led to increasing awareness of the scarcity and foreseeable exhaustion of the planet's energy resources. Many architects and other agents involved in the construction sector and research advocated reclaiming traditional building materials and techniques, in an attempt to find an acceptable balance between the functional and aesthetic demands of current construction and the parameters of bioclimatic architecture.

In Spain, although later than in other areas, this movement has also gained force and in the last 20 years, dwellings and all types of buildings constructed with earth have proliferated.

The traditional wooden formwork and manual compacting currently exist alongside formworks produced by the concrete industry, although the technique is gradually being modernised.

This paper draws attention to the significant diversity among the typologies of rammed earth buildings constructed in Spain in recent years. We believe this diversity provides evidence that this thousand-year old construction technique has returned from unjustifiable neglect to reassert itself, and now has a promising future.

Keywords: rammed earth, current techniques, examples, earth, construction.
Informes de la Construcción Vol. 63, 523, 21-34, julio-septiembre 2011 ISSN: 0020-0883 elSSN: 1988-3234 doi: 10.3989/ic.10.015

\footnotetext{
(*) Universidad Jaume I de Castellón.

${ }^{(*)}$ Conselleria de Medi Ambient, Aigua, Urbanisme i Habitatge de la G. Valenciana. Persona de contacto/Corresponding author: ferminfont@terra.es (F. Font)
}

Fecha de recepción: 24-02-10 


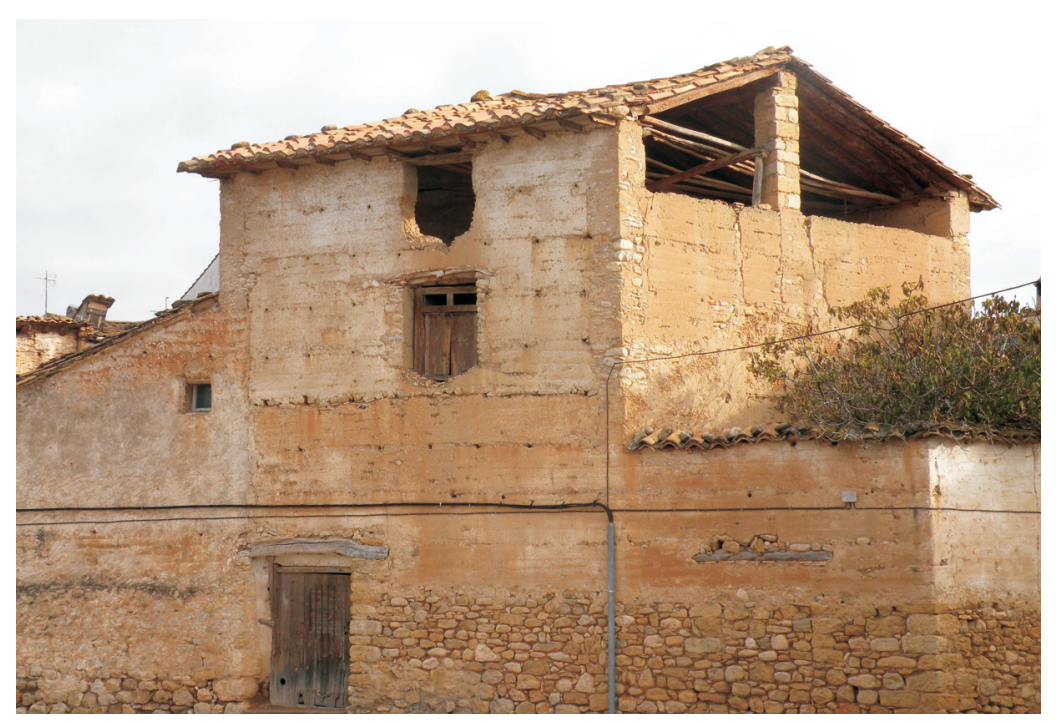

1. Antigua vivienda de tapia en la comarca de Els Ports. Castellón

1 G. Minke ha llevado a cabo más de 20 proyectos de investigación en el campo de las construcciones ecológicas, viviendas de bajo costo y especialmente en el campo de la construcción con tierra. Con amplia experiencia como experto internacional, ha diseñado numerosas edificaciones donde el barro es el material predominante, presentado ponencias en más de 60 conferencias internacionales, publicado libros (4) y artículos en revistas especializadas sobre la construcción con tierra.

2 Julián Salas Serrano, Doctor Ingeniero Industrial, es uno de los mayores expertos mundiales en habitabilidad básica y en tecnologías para viviendas de interés social. Es investigador del Instituto de la Construcción E. Torroja y director de la Cátedra UNESCO en Habitabilidad Básica (UPM ETSAM, Madrid). $\mathrm{Ha}$ impartido numerosos cursos, publicado 6 libros, realizado asesorías y dirigido conjuntos habitacionales en diversos países.

\section{INTRODUCCIÓN}

Hace 20 años publicamos el libro El tapial: una tècnica constructiva mil.lenària (1), una obra escrita en catalán que intentó acercar la arquitectura de tierra cruda, y la técnica de la tapia en particular, a los profesionales del sector y al público en general, dando a conocer este antiguo método de construcción de muros, sus características principales y sus posibilidades de utilización futura en la edificación.

El libro venía a ocupar, siquiera parcialmente, un para nosotros evidente e inexplicable vacío: apenas había documentación escrita sobre este método de construir desaparecido casi por completo en nuestro país a mediados del siglo XX. La tapia, la vieja técnica de apisonar tierra humedecida dentro de un encofrado llamado tapial, coincidiendo con la irrupción de materiales industrializados y las facilidades para el transporte de mercancías, estaba condenada inexorablemente al olvido. Nos pareció injustificable la pérdida del conocimiento de esta técnica constructiva con la que se han edificado incontables muestras arquitectónicas bellísimas, tanto de carácter monumental -baste recordar el complejo de la Alhambra de Granada- cuanto, sobre todo, popular, pues España cuenta con un amplísimo patrimonio arquitectónico repartido en la práctica totalidad de su territorio hecho de tierra compactada. (Figura 1).

En Europa las cosas fueron de otra manera. Tras la crisis energética de finales de los años setenta del pasado siglo, la tierra como material de construcción despierta el interés de un sector de la población y se inicia, tímidamente al principio, el rescate de materiales y antiguas técnicas constructivas que pudieran suponer una alternativa viable al encarecido y depredador proceso edificatorio imperante.
Sin duda también contribuyó a este despertar la celebración de la Conferencia HABITAT 76 para los asentamientos urbanos, auspiciada por la ONU y celebrada en Vancouver (Canadá) en 1976, donde 132 países consiguieron alcanzar unos acuerdos de principio plasmados en unos postulados que desde entonces son considerados en las políticas habitacionales en algunos de esos países, particularmente latinoamericanos. Algunas de las conclusiones finales incidían claramente en la necesidad de revalorizar las técnicas y materiales autóctonos como vía para paliar la carencia de viviendas en el Tercer Mundo.

A principios de los años ochenta surgen en Europa todo tipo de iniciativas edificatorias e investigaciones en torno a la utilización de la tierra cruda para los nuevos desafíos de la construcción sostenible y como experiencias para aplicar en los países más deprimidos. En este punto es de justicia citar la labor llevada a cabo desde entonces por el grupo CRATerre en Francia, plasmada en diversas iniciativas entre las que hay que destacar la experiencia piloto de construcción de 65 viviendas levantadas con tierra sin cocer cerca de Lyon en 1985 conocida como "Domaine de la Terre" (2), así como los magníficos trabajos que viene realizando en Austria y Alemania el innovador constructor Martin Rauch (3) o las iniciativas llevadas a cabo en este último país por el arquitecto Gernot Minke', catedrático de la Universidad de Kassel, entre otros ejemplos notorios.

También en otros continentes arquitectos innovadores han conseguido conciliar las exigencias funcionales y estéticas de los edificios de viviendas con los parámetros de la arquitectura bioclimática, Ilevando a cabo encomiables modernizaciones en la milenaria técnica de la tapia. Cabe citar entre ellos al arquitecto y constructor norteamericano David Easton, principal renovador de la construcción con tierra apisonada en USA desde los años setenta, que ofrece una enriquecedora muestra de las posibilidades plásticas y arquitectónicas de la tierra en sus diseños, logrando una envidiable integración de los volúmenes en el entorno. Pero los mismos efectos de gratitud recíproca entre el medio y el edificio podemos encontrarlos en iniciativas emprendidas en países como Australia o Canadá.

En España no es sino a mediados de los años ochenta del siglo pasado cuando comienza a renacer el interés por este humilde material. En 1983 el ingeniero Julián Salas Serra$n^{2}$ funda en el Instituto Eduardo Torroja, el equipo de investigación de "Tecnologías de viviendas de Muy Bajo Coste". Un año después se crea el Centro de Investigación 
de Técnicas y Materiales Autóctonos de Navapalos (Soria), dirigido por el arquitecto Erhard Rohmer, donde, desde el año 1985 se han impartido numerosos cursos de formación en construcción con tierra, celebrándose hasta el año 2006 encuentros de trabajo en los que han participado los más destacados especialistas internacionales en la materia, convirtiéndose pronto en una referencia y lugar de encuentro de profesionales europeos y latinoamericanos.

Tras estas iniciativas, diversas entidades, profesionales y universidades han venido realizando proyectos de construcción de viviendas, jornadas, congresos, cursos de formación, publicaciones, estudios e iniciativas de toda índole para recuperar y poner en valor estas arquitecturas que parecían abocadas a su desaparición. Citaremos, por ejemplo, el Centro de Investigación de la Arquitectura Tradicional de Boceguillas (Segovia) ${ }^{3}$, comandado y auspiciado por el Departamento de Construcción y Tecnología Arquitectónica de la Universidad Politécnica de Madrid, los proyectos de investigación y grupos de trabajo creados en las universidades de Sevilla, Granada y Valladolid, o el foro de internet Arqui-Terra promovido por el arquitecto técnico José María Sastre.

La tierra, tal y como ocurre desde hace siglos, es un material que nuevamente empieza a formar parte de la vida real, la que respira, pero que en muchas ocasiones sucumbe ante las exigencias legales, a pesar del dechado de bondades que este material ofrece: su carácter saludable e inofensivo para el ocupante de la vivienda, su amplia disponibilidad, su excelente comportamiento térmico, su indiscutible adaptación al paisaje, sus posibilidades formales y estéticas de gran fuerza visual (Figura 2), o su reciclabilidad indefinida, son solamente algunas de ellas.

Estas propiedades, apreciadas desde siempre por la arquitectura popular, nos permiten albergar esperanzas en el impulso de la vieja técnica de la tapia en esta época de emergencias energéticas y preocupación social por un desarrollo más sostenible. No obstante será imprescindible trasladar sus virtudes a parámetros mesurables, relegar deliberadamente las visiones románticas para contrastar sus cualidades con las de otros materiales tecnológicamente más avanzados. Será necesario avanzar en la investigación, tanto del material cuanto de la técnica constructiva y los medios auxiliares asociados, para lograr una arquitectura contemporánea con perspectivas de competir económicamente con los materiales y las técnicas convencionales.

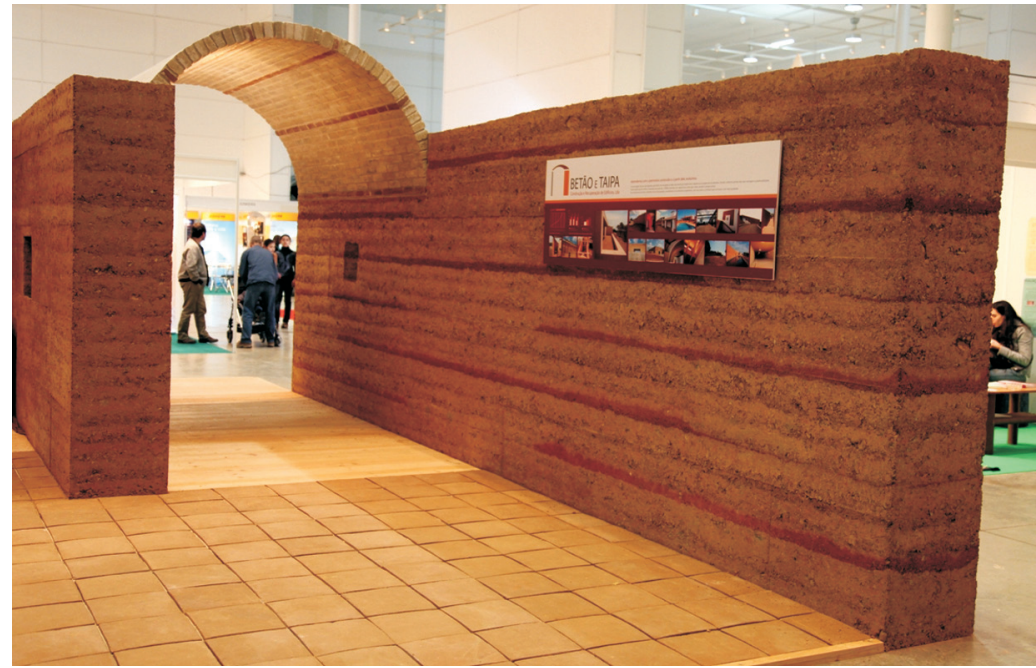

Uno de los obstáculos para lograr un impulso de la construcción con tierra sin cocer es la ausencia de soporte normativo, pues lo cierto es que en España esto es algo que, hoy por hoy, es difícil que pueda ir más allá de su empleo en el patrimonio monumental o en iniciativas impulsadas por promotores y arquitectos empecinados en construir con este material. En este ámbito ha significado un avance importante a nuestro entender la aprobación en el año 2008 de la Norma UNE sobre bloques de tierra comprimida (5).

A las tradicionales técnicas del adobe y de la tapia se unió en los años cincuenta del pasado siglo el Ilamado "Bloque de Tierra Comprimida", conocido por las siglas BTC, pieza de dimensiones similares a la del ladrillo corriente realizada con tierra prensada y estabilizada con cemento, cal o con fibras vegetales para mejorar el aislamiento térmico, que actualmente se comercializa en numerosos países europeos $y$, aunque todavía de forma incipiente, también en España.

Por otra parte cabe decir que en el Ministerio de Vivienda parece constatarse por fin el interés por incorporar al actual CTE, que tanto ignora la construcción con tierra, este material y las técnicas tradicionales asociadas a él, y también, que está en elaboración la norma UNE sobre el tapial. Estas iniciativas pueden constituir, sin duda, un impulso notable para la construcción con tierra y su actualización. Esperemos que se materialicen pronto.

Las cosas, pues, parece que pueden mejorar. Ya desde el año que editamos el libro mencionado han ido apareciendo todo tipo de trabajos de investigación. Surgen también, por toda la geografía española, sobre todo en Catalunya (Figura 3) y la meseta castellana, como tendremos ocasión de comprobar seguidamente, edificaciones de tapia, adobe
2. Muro de tapia con extendido de capas de tierras de distintas tonalidades en la Feria de Energías Renovables celebrada en la localidad portuguesa de Serpa en 2009 en el que se manifiestan las enormes posibilidades estéticas de la tapia. Muro realizado por la empresa Betão

El CIAT fundado en 1996 tiene como objetivo principal el fomento de actividades encaminadas a la investigación, la difusión y la protección de la arquitectura tradicional impartiendo cursos a estudiantes universitarios y organizando jornadas y encuentros entre investigadores y profesores. e Taipa. Fuente: B.e Taipa 


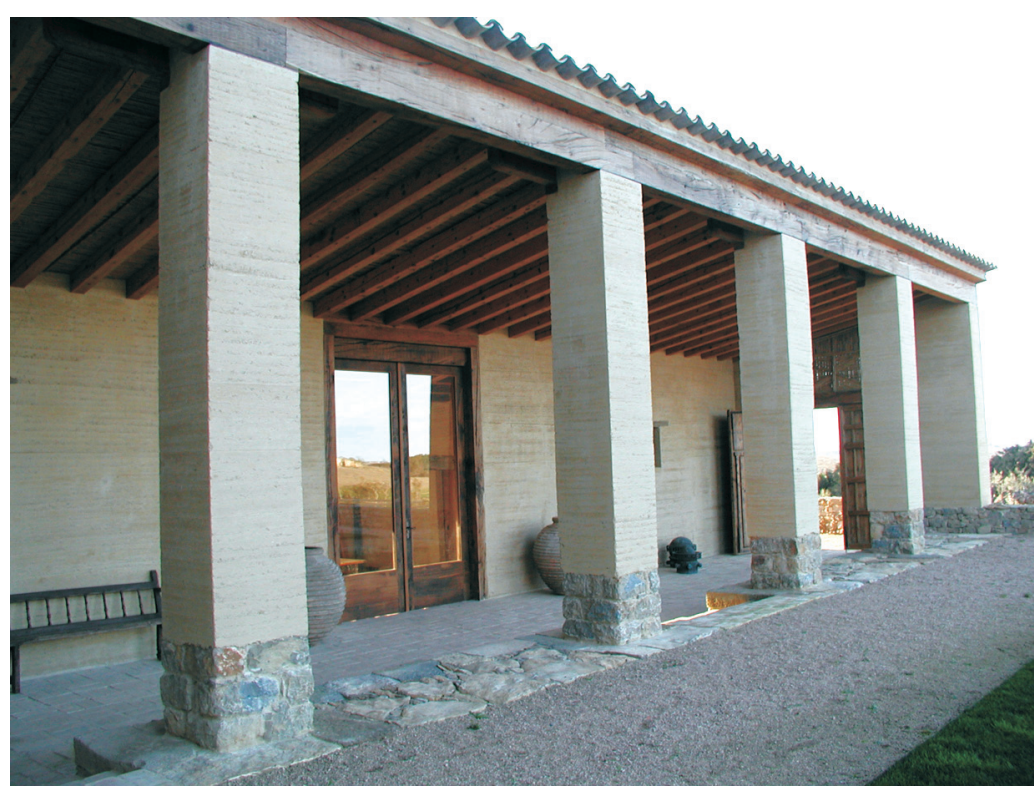

3. Vivienda de tapia construida en el año 2008 en Pals (Girona). Proyectada por Auquer Prats Arquitecturas. S.L. y construida por Construccions y Reformes Germans Ferrer. Fuente: A.P. Arquitecturas S.L. o BTC, principalmente viviendas unifamiliares. Por nuestra parte, a finales del año 2009 publicamos un nuevo libro (Arquitecturas de tapia) (6) en el que intentamos recoger precisamente la evolución acaecida en la recuperación de esta antigua técnica y reseñamos algunos notables ejemplos de realizaciones de nueva planta y diversas intervenciones en el patrimonio monumental español.

Antes de realizar un breve recorrido por algunas de las más destacables realizaciones de tapia en nuestro país, llevadas a cabo entre los años 2005 y 2010 y algunas todavía en fase final de terminación, creemos necesario explorar las nuevas exigencias demandadas al material básico e introducirnos en los medios auxiliares necesarios para su puesta en obra.

\section{NUEVAS EXIGENCIAS EN RELACIÓN AL MATERIAL}

La tierra apta para la construcción de tapias ha de estar compuesta por arcilla, limo, arena y grava. Dependiendo de la proporción de estos elementos y de la calidad de la arcilla obtendremos distintos tipos de tierra con diferentes propiedades. Así pues, con una arcilla de calidad y una adecuada proporción de los cuatro componentes, acompañados de una cierta cantidad de agua, obtendremos un material válido, en principio, para la construcción de muros de tierra apisonada.

Ahora bien, ¿cómo podemos estar seguros de que la tierra de que disponemos es apropiada? Antiguamente, el constructor anónimo hacía uso de su experiencia y de elementales pruebas de campo de carácter sensorial que proporcionaban una relativa seguridad de su bondad. Sabía que la tierra tenía que contener una cierta cantidad de grava que ayudara a incrementar la estabilidad de la mezcla y la resistencia del muro, además de arena y de limo, y que una adecuada proporción de arcilla le confería la necesaria cohesión y plasticidad, una vez evaporada el agua. Estos conocimientos eran, pues, fruto de la experiencia y de la transmisión oral de la técnica.

Actualmente una elección del material basada únicamente en estos argumentos es insuficiente. Es necesario ofrecer una caracterización del material más precisa pues se nos presentan exigencias técnicas, de acabados, del proceso de ejecución, y en un futuro próximo, nuevas normativas, a las que habrá que responder con solvencia. Nos referimos, entre otras, a las solicitaciones estructurales a las que se verá sometido un muro, compresión principalmente, su resistencia a la acción del agua y a la erosión de los paramentos, al monolitismo de la fábrica, a los requerimientos estéticos, al comportamiento térmico, etc. Es evidente que estas demandas no tenían antiguamente el mismo valor que ahora.

\subsection{Ensayos de laboratorio. La tierra}

Buena parte de las exigencias relacionadas han sido satisfechas en las edificaciones de tierra apisonada realizadas en España en la última década. Para verificar su cumplimiento se han Ilevado a cabo en la práctica totalidad de las obras que relacionamos en este trabajo el reconocimiento de suelos en laboratorio procediendo a la realización de las pruebas y ensayos siguientes:

- Análisis granulométrico (según UNE 103101:95)

- Análisis granulométrico de suelos finos por sedimentación (UNE 103102:95)

- Determinación de los límites de Atterberg (UNE 103103:94 y 103104:93)

- Determinación de los valores de retracción lineal.

- La determinación del tipo de arcilla para conocer la posible expansividad de esta y los estabilizantes más apropiados (7).

- Determinación de materia orgánica oxidable de un suelo por el método del permanganato potásico (UNE 103204/93)

- Determinación del contenido de sales solubles de un suelo. (UNE 103205:2006)

Además de determinar estos valores es habitual, y necesario para conocer el grado óptimo de humedad de la tierra y el futuro comportamiento de la fábrica la realización de los siguientes ensayos:

\section{-Ensayo Próctor modificado} (UNE 103501:94) 


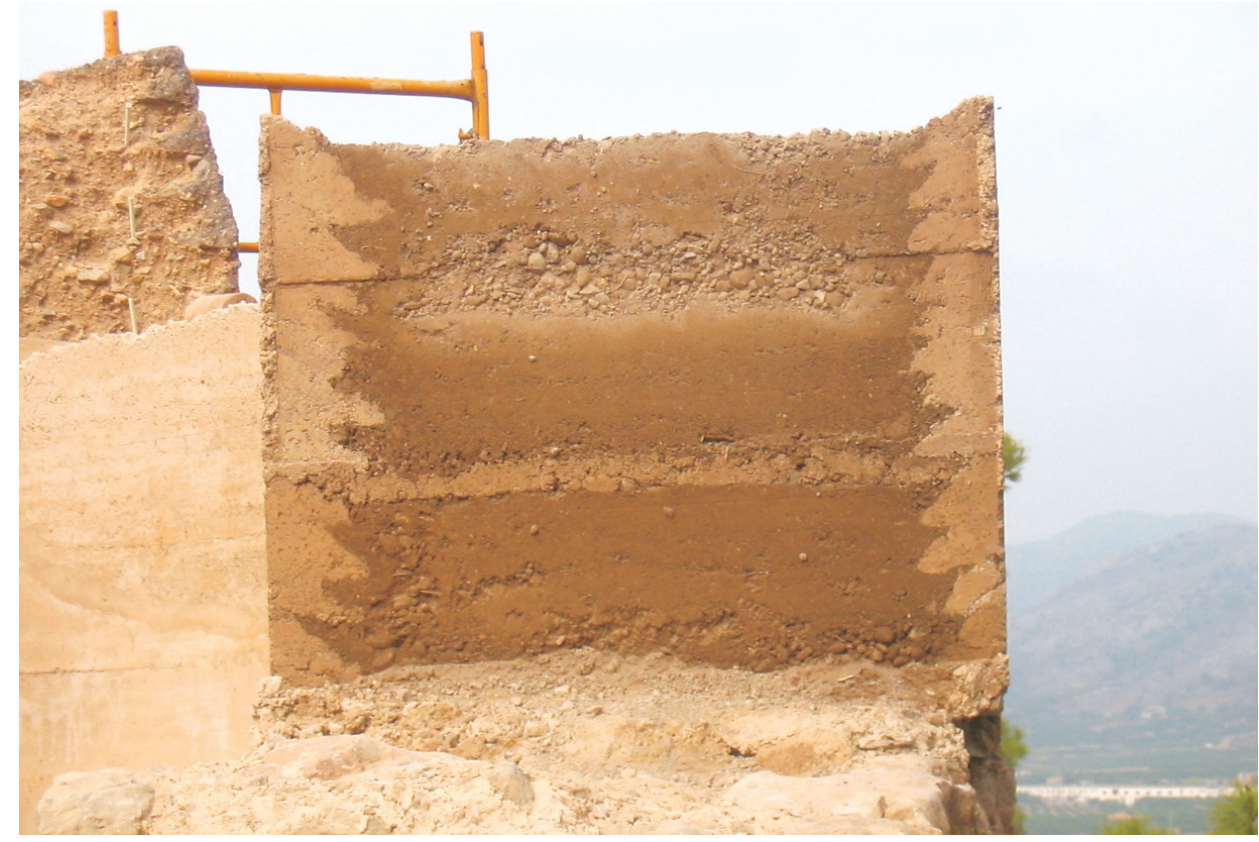

- Rotura de probetas a compresión simple (NLT 305:90).

La proporción existente de los distintos componentes ha de favorecer que los huecos dejados por los de mayor tamaño sean ocupados por los más finos. Conviene, por tanto, disponer de un material que posea una granulometría equilibrada, lo que en la caracterización de suelos se representa con una curva continua, así como una adecuada proporción de arcilla y una grava de tamaño menor de $20 \mathrm{~mm}$, si la tierra va a quedar vista, pudiéndose incrementar éste si los paramentos se van a revestir, o si el muro se va a realizar calicostrado, es decir, aquel que cuenta con un revestimiento de mortero de cal que se realiza al tiempo que se apisona la tierra (Figura 4).

Numerosos autores como Houben $(8,9)$ y Walker (10) y diversas normativas españolas como el antiguo Piet-70 (11) o la ya citada normativa de BTC (12), aportan recomendaciones y límites ciertamente dispares entre los que deben situarse los distintos componentes y el índice de Atterberg recomendado. En general se trata de orientaciones, pues, como dice Houben, algunas tierras pueden dar resultados satisfactorios aun no encontrándose dentro de estos límites. De hecho, en un trabajo de consolidación de tapias antiguas realizado en el año 2010, en el que hemos participado, los resultados de laboratorio no se encontraban entre los recomendados pese a ofrecer buenas prestaciones ${ }^{4}$.

La determinación del índice de retracción nos informará sobre la contracción de la

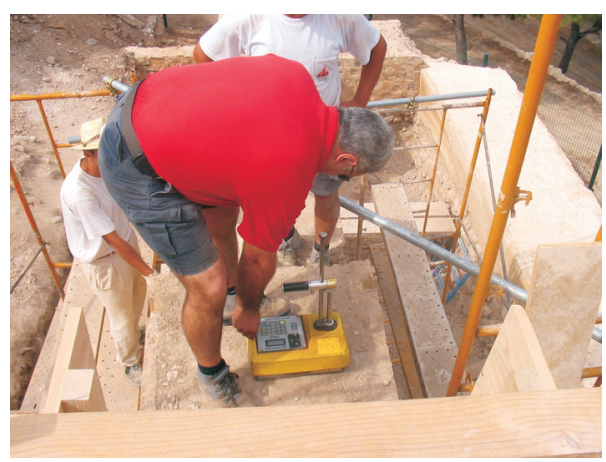

tierra apisonada el secarse. Aunque de esto ya se puede tener una idea tras la determinación de los límites de Atterberg, algunos proyectistas han optado por llevar a cabo el ensayo pues ofrece una información más precisa. Valores elevados comportan fuertes contracciones del material y, consecuentemente, grietas y fisuras en los paramentos que, además de perjudicar su acabado, son una vía de penetración de agua y el inicio de la degradación del muro. Para reducirla, en la construcción de la Escuela de niños de han añadido virutas de madera. En otros casos se han realizado correcciones granulométricas y/o incorporado aglomerantes.

De la calidad de la arcilla y de su porcentaje en la muestra, además de las posibles correcciones ya expresadas, se determinará la conveniencia de su estabilización mediante aglomerantes y cuál es el más adecuado.

Mientras que con el ensayo Proctor modificado se determina la humedad óptima para la puesta en obra de la tierra, con la Santa Eulalia, que después mostraremos, se

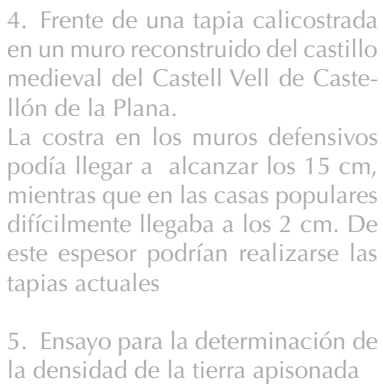

4. Frente de una tapia calicostrada en un muro reconstruido del castillo medieval del Castell Vell de Castellón de la Plana.

La costra en los muros defensivos podía llegar a alcanzar los $15 \mathrm{~cm}$, mientras que en las casas populares difícilmente llegaba a los $2 \mathrm{~cm}$. De este espesor podrían realizarse las tapias actuales

5. Ensayo para la determinación de la densidad de la tierra apisonada

${ }^{4}$ Se trata de la consolidación de muros en el recinto medieval del Castell Vell de Castellón de la Plana, en el marco de un proyecto redactado por el arquitecto Ignacio Gil-Mascarell, financiado por la Conselleria de Cultura de la Generalitat Valenciana. En las pruebas de laboratorio la curva granulométrica estaba lejos de aproximarse a las recomendadas. El porcentaje de arcilla era del $7 \%$ en peso del total, y el índice de plasticidad de 6,6, valores ligeramente inferiores a los aconsejados. Con ello la resistencia a compresión simple de la probeta Proctor de referencia dio 5,1 $\mathrm{MPa}$, y la respuesta a la erosión hídrica de los paramentos sin crosta ni estabilizantes realizados en el año 2005 es satisfactoria 

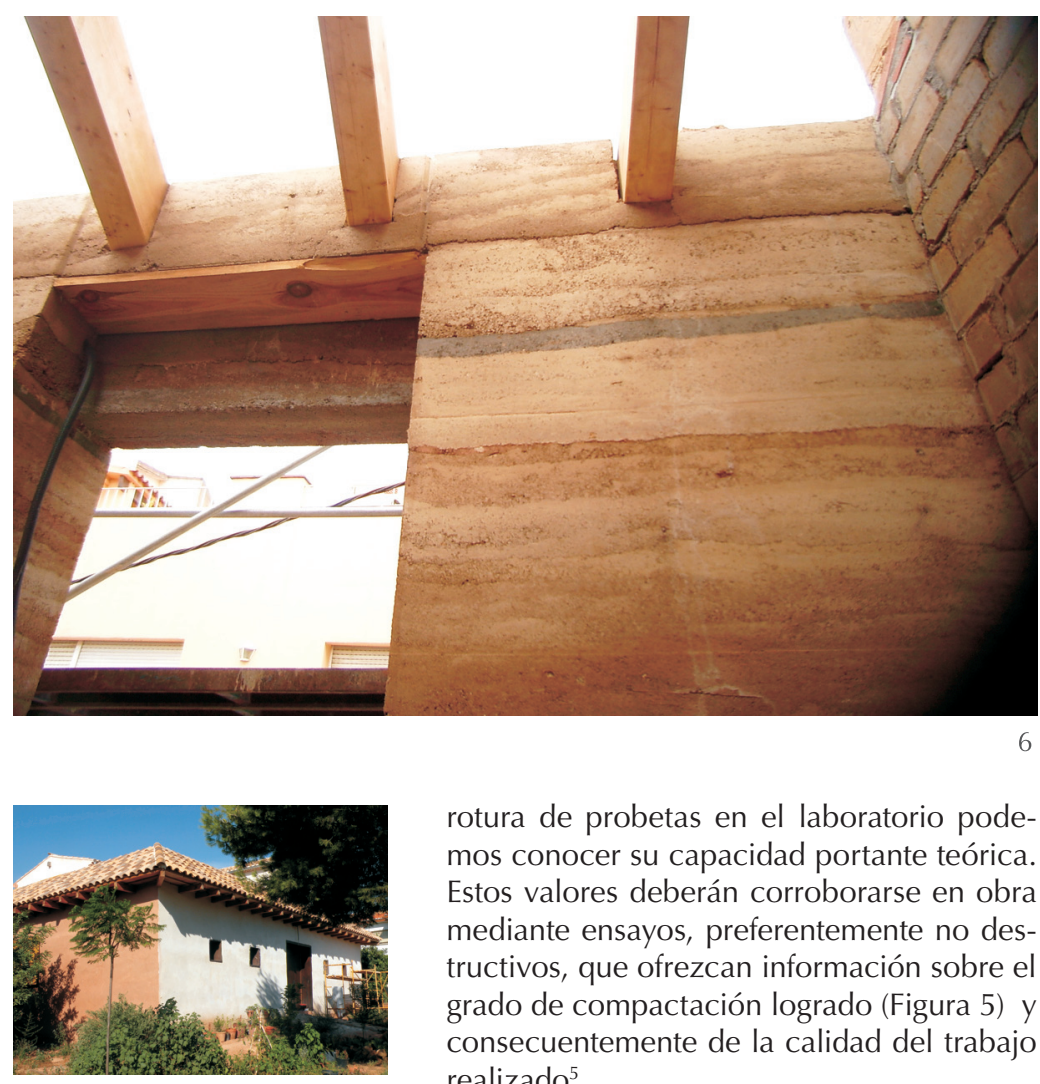

7

6. Paramento de un muro de tapia de una vivienda en Sant Feliu de Guixols con franjas de tierras coloreadas con pigmentos minerales de distintas tonalidades. Edificación proyectada por los arquitectos Gabi Barbeta y Jordi Caminero y construida por Construcciones Delgado S.L. Fuente: G. Barbeta

7. Vivienda de tapia construida en el año 2006 en la localidad del El Puig (Valencia) con los paramentos revestidos con mortero de cal

${ }^{5}$ En la obra citada del Castell Vell se estableció un control de calidad consistente en la realización y rotura de 3 probetas a distintas densidades con la realización de una gráfica grados de compactación/resistencia a compresión. La toma del grado de compactación en el muro se realizó en diversos puntos mediante el ensayo de isotopos radiactivos (ASTM D2292-81 y ANSI/ASTM D3017-78). Finalmente se trasladaron a la gráfica para conocer la resistencia a compresión del muro. Se estableció en proyecto que ninguna de las tomas podía dar valores inferiores al 95\% de la compactación del Proctor de referencia. rotura de probetas en el laboratorio podemos conocer su capacidad portante teórica. Estos valores deberán corroborarse en obra mediante ensayos, preferentemente no destructivos, que ofrezcan información sobre el grado de compactación logrado (Figura 5) y consecuentemente de la calidad del trabajo realizado 5 .

\subsection{Estabilizaciones de la tierra}

La estabilización ha sido una práctica común desde antiguo. Así lo testimonia, entre otros autores, I. Valverde en su trabajo sobre las murallas musulmanas de Granada (13), en el que se pone de manifiesto la considerable cantidad de cal adicionada a la masa de tierra.

Pero el estabilizante más utilizado actualmente es el cemento, el cual, añadido en seco en proporciones adecuadas consigue incrementar notablemente la resistencia del muro a la acción del agua y a la compresión.

Decidirse por el empleo de la cal aérea o por el cemento va a depender principalmente de la calidad y porcentaje de la arcilla, para suelos arenosos y la cal para los arciIlosos (14). Si bien las recomendaciones más frecuentes sugieren porcentajes entre el 6 y el $10 \%$ del total en peso, es conveniente la realización de ensayos previos. Podemos citar que en las obras que mostraremos la cantidad de cemento se encuentra entre estos valores, empleándose el cemento blanco con la intención de no alterar la tonalidad de la tierra. En alguna de ellas se ha estabilizado con los dos aglomerantes, cemento y cal aérea, en porcentajes del 5\% cada uno.

Hay que resaltar el trabajo de investigación llevado a cabo en este campo por la Universiendo, por lo general, apropiado el cemento sidad Politécnica de Madrid (15), en el que se ha estudiado la mezcla de tierras con resinas, puzolana de síntesis, betún y muchos otros productos destinados a mejorar el comportamiento de la tierra apisonada.

\subsection{Preparación del material}

El proceso de preparación se realizaba tradicionalmente con medios manuales en su totalidad, limitándose a apartar los guijarros y a deshacer los terrones cuando la tierra era arcillosa. Se comprobaba asimismo el grado de humedad, estimándolo correcto si apretando con la mano un poco de tierra, no se adhería a esta al abrirla y conservaba la forma.

Actualmente, para obtener un material homogéneo, se procede a voltear la tierra con una excavadora ligera del tipo manitou o similar, mezclando el material como antiguamente se hacía con los útiles manuales, que en cualquier caso siempre son necesarios. Para estas operaciones también se hace uso de las cavadoras empleadas en la agricultura.

De manera similar se procede para mezclar la tierra con la grava o arena, si se necesita de corrección granulométrica, o para la mezcla del suelo con los aglomerantes. Una vez homogeneizado el material se le añade el agua necesaria de manera controlada, pues la humedad de la tierra para la tapia difícilmente será superior al 10\% en peso.

Hay que destacar que en nuestro país aún no se comercializa maquinaria específica para estos fines, empleándose las descritas y otras procedentes del campo de las obras públicas.

\subsection{Acabado y protección de los paramentos}

Las agradables texturas, la simplicidad de las superficies conseguidas y la riqueza de tonalidades que posibilita la tierra seducen de manera poderosa. Estos atractivos vienen a explicar el que en la mayoría de construcciones se haya optado por que el propio material se visualice claramente en los paramentos. No obstante, esta opción demanda que las fábricas queden adecuadamente protegidas para minimizar su erosión por la acción del agua de lluvia, o, al menos, que se pueda controlar su degradación. En este sentido M. Rauch sugiere: "¿por qué no hacer posible una erosión calculada con un proceso de envejecimiento controlado, como un elemento formal más?" (16), introduciendo un nuevo enfoque con enormes posibilidades plásticas a explorar.

En España se ha estado experimentando en la aplicación de sustancias hidrófugas y di- 
ferentes tipos de consolidantes como tratamientos superficiales que ayuden a satisfacer las nuevas exigencias demandadas. Han sido los productos hidrofugantes los más empleados en las obras realizadas y entre éstos las resinas de silicona. Los consolidantes han tenido menos adeptos, pero será necesario experimentar en este campo para mejorar la respuesta de las fábricas a la erosión.

El bello efecto cromático de la tierra apisonada se enriquece, en ocasiones, con particulares efectos visuales. Tal es el caso de los paramentos de la piscina de Toro, con el extendido de lechos de mortero de cal intercalados entre las tongadas de tierra apisonada, o el recurso empleado con frecuencia por el constructor Martin Rauch de verter tierras de diferentes tonalidades. Un efecto similar se consigue añadiendo colorantes minerales, como en el muro de la imagen de una vivienda en construcción en Sant Feliu de Guixols (Figura 6).

Cuando la fábrica no ha de quedar a la vista se puede extender un revestimiento continuo, sea un mortero de cal (Figura 7) o de arcillas preparadas. Otra alternativa es realizar la tapia calicostrada, pero observamos que esta solución, pese a ofrecer garantías de durabilidad y un bello acabado, no goza del interés de los arquitectos. En cambio es de esta manera como se construyeron buena parte de las tapias antiguas y por tanto habrá que recurrir a esta modalidad en la restauración monumental.

\section{NUEVAS EXIGENCIAS EN RELACIÓN A LOS MEDIOS TÉCNICOS AUXILIARES}

El tapial que se empleaba antiguamente y los pisones eran de madera. Se confeccionaba con madera dura, seca y resistente, con unas dimensiones y características que provenían de la tradición, de la probada experiencia de su bondad, cumpliendo con holgura los requisitos de solidez, maniobrabilidad y funcionalidad demandados (Figura 8). En el molde se irá compactando la tierra por tongadas con ayuda del pisón, lo que constituye la esencia de esta milenaria técnica constructiva.

Esta manera de construir resultaba muy económica y no requería de conocimientos especializados. El empleo masivo de mano de obra, barata entonces, y las exigencias de seguridad en el trabajo no tenían la relevancia de ahora, pues la imagen de dos tapiadores sobre un muro a 5 metros de altura sin protección alguna, apisonando la tierra y desplazando los tableros, es hoy en día impensable. Actualmente hay unas medidas de seguridad ineludibles, impuestas por la legislación y por el sentido común. Se partía, pues, de una tradición transmitida de gene- ración en generación, donde la costumbre y la capacidad de trabajo de los operarios eran los aliados imprescindibles.

Hoy día, para que esta manera de construir gane presencia en la edificación es necesario un abaratamiento de los costos, que pasa inevitablemente por el incremento en los rendimientos de producción, introduciendo mejoras en los medios auxiliares a emplear. $\mathrm{Y}$, en efecto, en este ámbito se ha avanzado sustancialmente.

\subsection{Los tapiales o encofrados}

Ya a mediados del siglo pasado se experimentaron posibles mejoras en los tapiales tradicionales. Así ocurrió, por ejemplo, en Australia en 1952, donde se construyó un modelo inspirado en el tradicional que se desplazaba horizontalmente por medio de pequeños rodillos. Se han ido ideando tapiales continuos, deslizantes, concebidos para ser desplazados en vertical en su totalidad, y todo un conjunto de elementos especiales en $L$ y en $T$ para mejorar los encuentros entre las fábricas.

En Europa en las últimas décadas han ido empleándose diferentes tipos de encofrados provenientes de la industria del hormi-
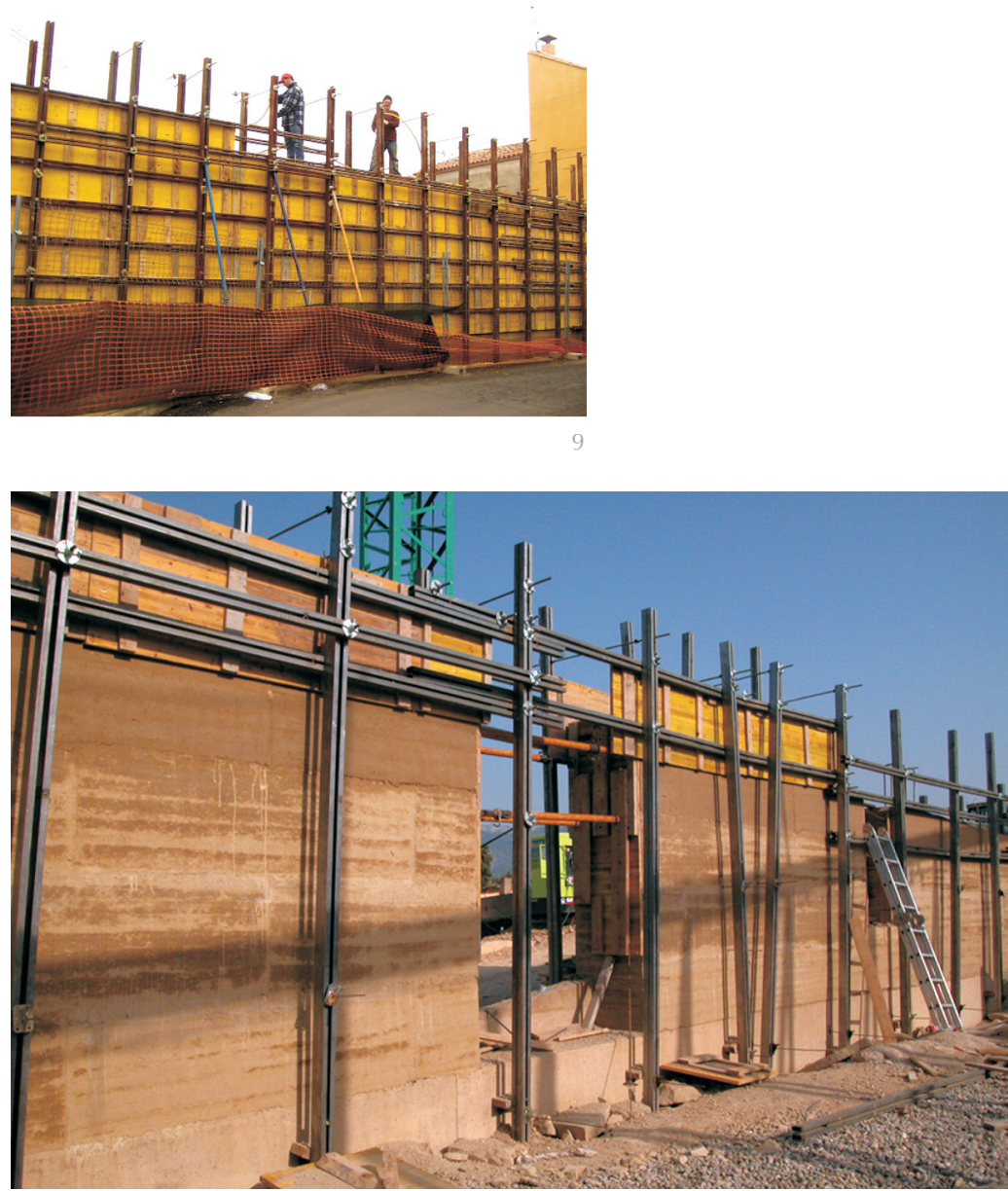

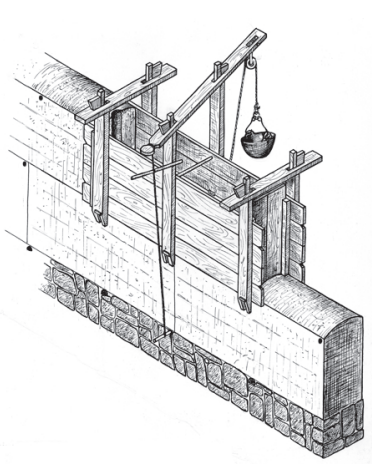

8. Tapial tradicional de la comarca de Els Ports de Castellón

9. Encofrado para la construcción de las tapias de la piscina municipal de Toro (Zamora). Fuente: J.M. Sastre 10. Encofrado para la construcción de los tapiales de la bodega de Lanciego (Álava). Fuente: P. Basañez 
11. Vertido de la tierra al tapial para su apisonado desde una maquina de elevación. Fuente: Betão e Taipa

12. Pisón neumático de la marca Sullair. Compactador ligero óptimo para hacer tapias gón que, lejos de las repetidas operaciones que exigían los tradicionales, posibilitan la ejecución de grandes lienzos de muro, reduciéndose apreciablemente los tiempos de ejecución.

Con el empleo de estos encofrados y de maquinaria de elevación es cuando se ha podido avanzar realmente, acometiéndose obras de gran envergadura. Baste observar atentamente los encofrados integrales que se han utilizado en la construcción de la piscina municipal de Toro (Figura 9) o, ya en otra escala, los de la Capilla de la Reconciliación en Berlín, levantada en el año 2000 con la participación del mencionado M. Rauch (17).

Con todo, pese a los avances acaecidos, en España los tapiales de madera similares a los tradicionales conviven actualmente con los encofrados industriales. Dos concepciones distintas, pues mientras que en los primeros se repiten en numerosas ocasiones las operaciones de montaje y desmontaje, siendo, en cambio, manejables y no requieren de maquinaria de elevación, en los segundos se pueden realizar grandes paños de muro de una sola vez. Aunque éstos son más caros
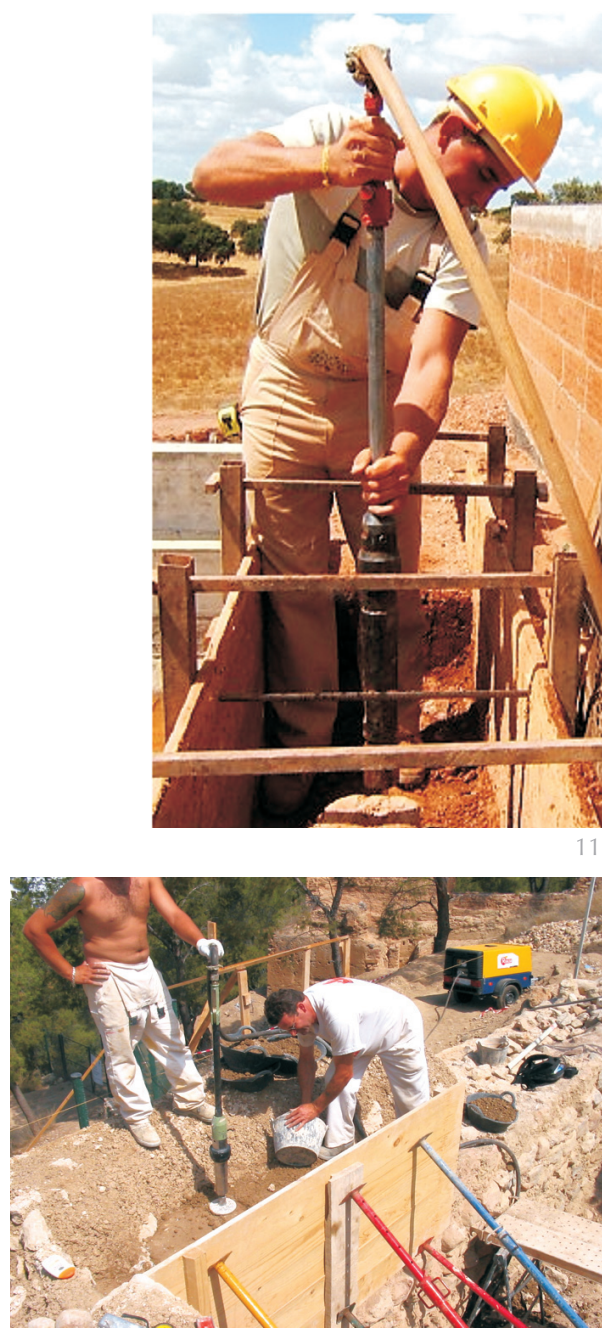

que los primeros, resultarán, en la mayoría de los casos, más rentables.

Describiremos seguidamente dos de los tipos de encofrados industriales que se vienen empleando en España:

Un modelo muy común es el que se emplean tableros de madera tricapa con un conjunto de correas horizontales y verticales conectadas mediante varillas y tuercas, atirantándose el conjunto con varillas roscadas tipo diwidag (espadas) con tuercas y aceros lisos de $8 \mathrm{~mm}$ tensados y sujetos con ranas. Los paneles se van montando verticalmente al ritmo que se apisonan las tierras, pudiendo ir desmontándose los situados en las hiladas inferiores ya compactadas. Una vez desmontado el encofrado habrá que cortar los tirantes de acero (Figura 10).

Otro modelo se confecciona con tableros fenólicos con marco metálico sujetos con varillas envainadas en tubos de PVC y con tuercas. Puede montarse una estructura para ir colocando los tableros tal como se va apisonando la tierra. Sin duda es una solución cara, resultando más económico ir montando los paneles corridos en cada hilada. Extraídas las varillas o diwidag quedaran en el interior del muro las vainas con los característicos orificios de los muros de hormigón. Para el desplazamiento de los tableros requeriremos de maquinaria de elevación.

Cabe decir que, en cualquier caso, es muy recomendable considerar durante el diseño de la edificación las dimensiones y tipo de encofrado a emplear, a fin dar solución a algunos de los problemas que esta técnica constructiva presenta y resolver los acabados de manera satisfactoria.

\subsection{El vertido de la tierra en el encofrado}

Antiguamente se vertía la tierra con espuertas que se elevaban con la ayuda de una polea sujeta al tapial. Esta manera de proceder es adecuada si el ritmo de compactación es reducido, pero con pisones mecánicos es aconsejable el empleo de maquinaria de carga y elevación. Es apropiado para esta tarea, y así se hace en muchas de las obras actuales, disponer de una máquina cargadora polifuncional que eleve la tierra hasta la orilla del encofrado para que los propios tapiadores puedan ir vertiéndola según su ritmo de trabajo (Figura 11).

\subsection{Los pisones}

La aparición de los sistemas mecánicos de apisonado ha supuesto un avance de gran calado en esta técnica constructiva. Con ellos se logra, con menor esfuerzo, un au- 
mento notable de los rendimientos, al tiempo que un mayor grado de compactación, con las consecuentes mejoras de las prestaciones mecánicas y de respuesta a la erosión hídrica, lo que podrá comprobarse mediante los correspondientes ensayos.

Pese a las ventajas de los pisones mecánicos, el de madera sigue empleándose en muchas de las obras que se están ejecutando. Pensamos, no obstante, que poco a poco irán siendo relegados por los mecánicos. El más utilizado es el impulsado por aire comprimido con el que se puede graduar la potencia de impacto deseada. Hay modelos muy ligeros y cómodos de manejar, como el que mostramos en la imagen (Figura 12), del que podemos dar fe de su idoneidad. Sin embargo ni este pisón ni otros similares se comercializan todavía en España.

También se utilizan los pisones eléctricos. Un modelo que se ha empleado en la vivienda de Aramaiona y que según Ekaiz Uribe, proyectista de la edificación, ofrece buenas prestaciones es el GSH-27 de Bosch con una placa de $20 \times 20 \mathrm{~cm}$. Así y todo, a nuestro entender, los neumáticos presentan mayores ventajas.

Otros medios mecánicos de apisonado como las bandejas vibratorias con cambio automático de sentido de la marcha o las apisonadoras de rodillos vibratorias se vienen empleando en Alemania y Austria con rendimientos de compactación elevados. Los primeros, apropiados solamente para suelos granulares, requieren, al igual que los segundos de encofrados industriales excepcionalmente robustos.

\section{EJEMPLOS}

Ha llegado el momento de presentar algunas de las más relevantes arquitecturas de tierra que se han realizado en España en los últimos años y otras que en estos momentos están en ejecución.

En la mayoría de las realizaciones que reseñamos los muros de tapia son el elemento característico que las identifica; en otras no son los protagonistas principales pero contribuyen sin duda a generar una atmósfera particular y a conferir a la edificación una marcada personalidad.

En algunas de estas obras se ha empleado el tapial tradicional de madera y el pisón manual, sobre todo en las viviendas unifamiliares, en otras, en cambio, los encofrados industriales descritos y los pisones mecánicos, sobre todo los neumáticos.

Estas edificaciones se han realizado principalmente con muros de tierra sin revestir, estabilizados con la adición de pequeños porcentajes de cemento o cal, y en algún caso también con correcciones granulométricas. En todas ellas se han hecho los ensayos de reconocimiento del suelo comentados.

Los ejemplos que vienen a continuación no pretenden más que dejar constancia de que en estos momentos existe un grupo de inquietos profesionales que han asumido el reto que supone aquí y ahora edificar con la antigua técnica del tapial, convencidos de las propiedades intrínsecas de la tierra, aprovechando desde luego las nuevas tecnologías. A nuestro juicio los resultados obtenidos son de incuestionable interés.

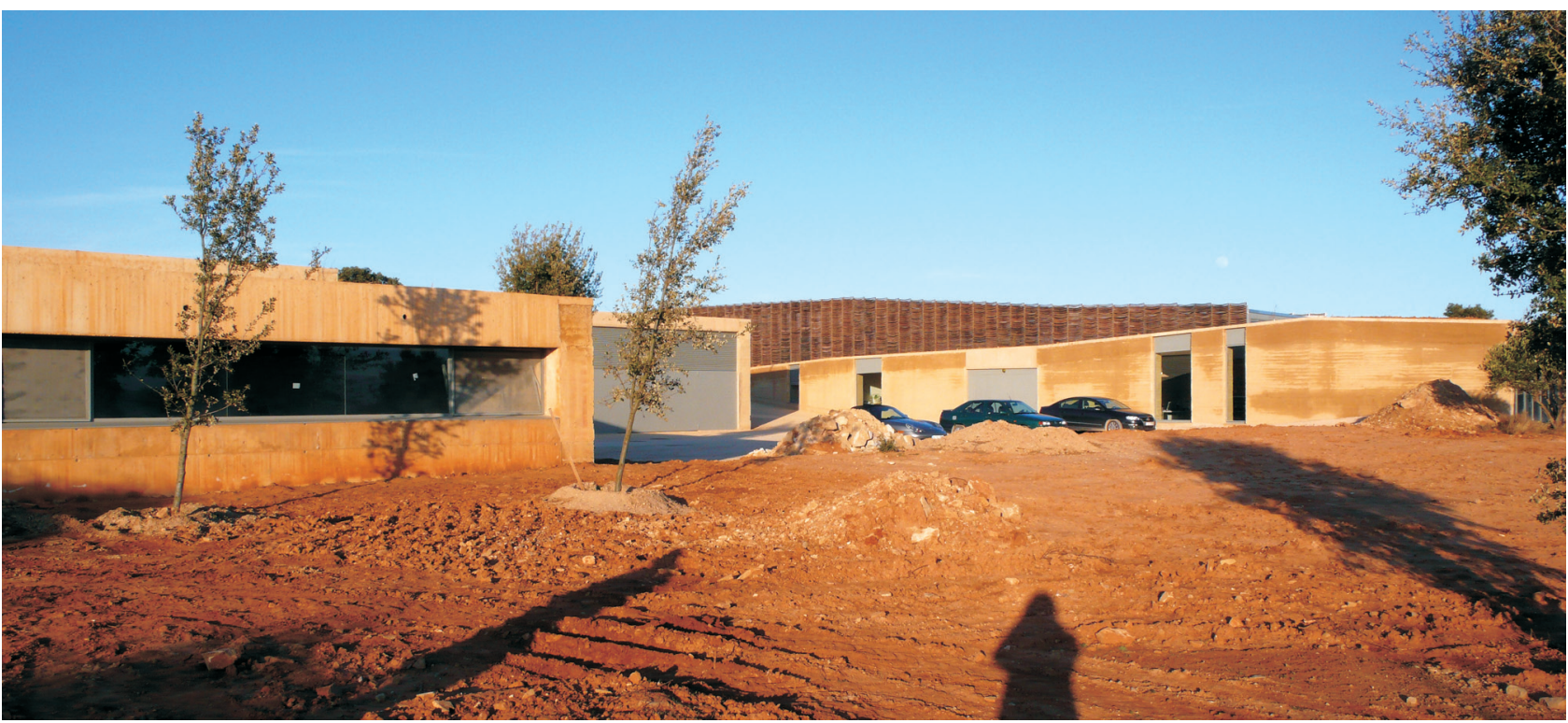



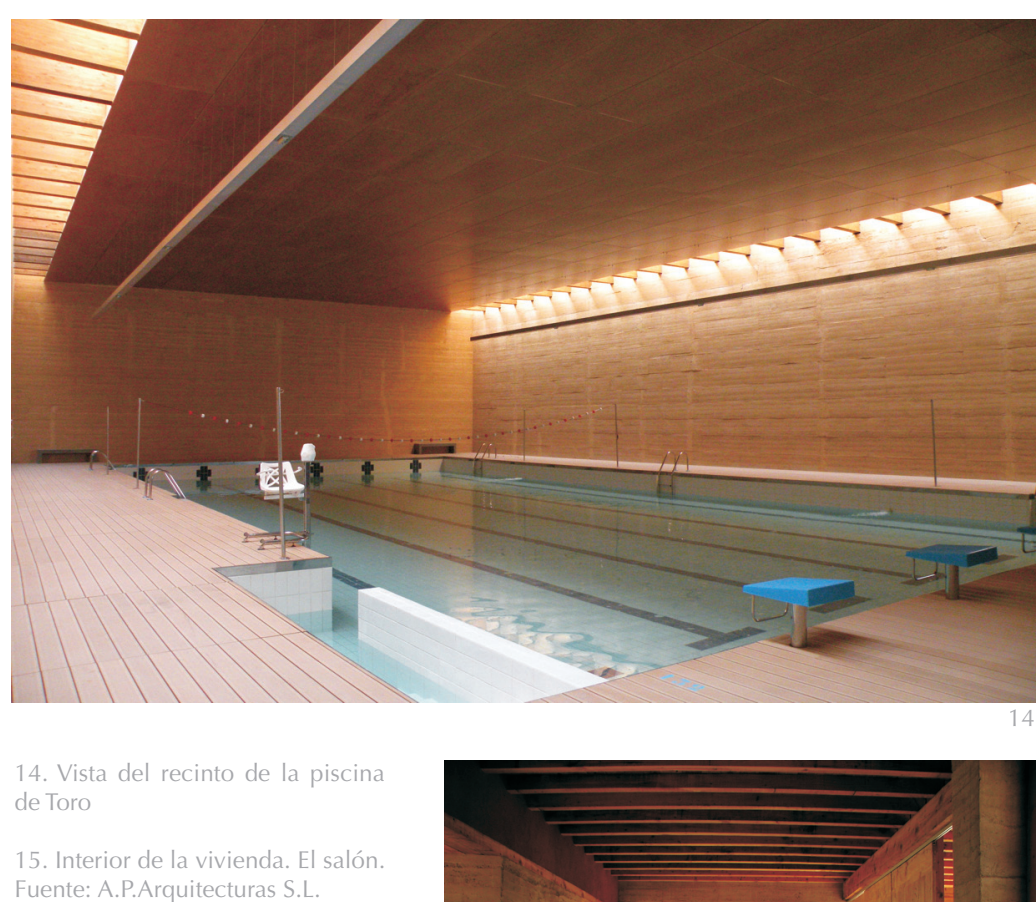

Fuente: A.P.Arquitecturas S.L.

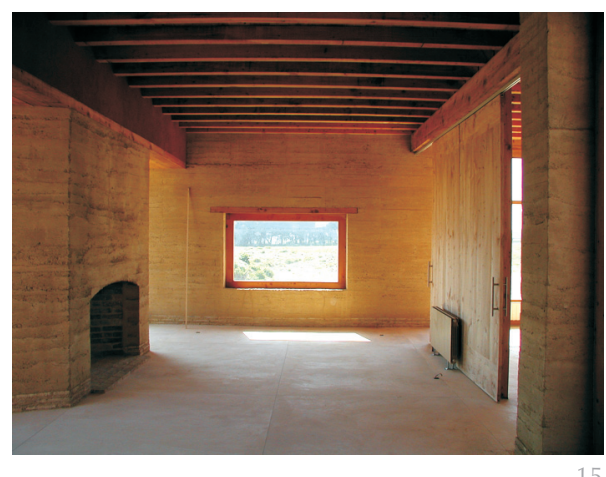

\subsection{Bodega en Lanciego (Álava)}

La bodega (Figura 13), promovida por la Compañía de Vinos Telmo Rodríguez, se compone de una serie de naves semienterradas orientadas en dirección norte a sur para facilitar la ventilación natural. La planta principal, parcialmente enterrada, comunica con las restantes mediante un patio abierto al que se accede desde distintas rampas. Únicamente la nave de elaboración tiene una planta alta, accesible desde el nivel superior para recoger la vendimia y para la fabricación de vino. La superficie construida total es de $3.310 \mathrm{~m}^{2}$.

Las cubiertas se recubren con tierra del lugar para incrementar su inercia térmica y favoreciendo su integración en el paisaje. Se ejecutan los muros de tierra apisonada para obtener una regulación natural de la humedad en el interior de las naves. La obra ha sido proyectada y dirigida por los Arquitectos Diego Garteiz y Paul Basañez, finalizándose la construcción al término de 2008.

La tipología estructural es de pórticos de pilares y vigas de hormigón armado, y muros de contención de hormigón, quedando los pilares embebidos en la masa de tierra compactada.
Elevados sobre zócalo de hormigón, los muros, con anchos que alcanzan los $70 \mathrm{~cm}$, se han construido con la tierra procedente de las excavaciones, estabilizándose con cemento blanco y cal aérea. No tienen misión portante, sino solamente de cerramiento.

Los encofrados empleados provienen de la industria del hormigón, con tableros de madera tricapa y un conjunto de correas horizontales y verticales conectadas mediante varillas $y$ tuercas, atirantando el conjunto con varillas roscadas (espadas) y aceros lisos de $8 \mathrm{~mm}$ tensados y sujetos con ranas. El apisonado se ha realizado con compactador neumático. Los trabajos de tapia han estado a cargo de la empresa portuguesa Betão e Taipa, Lda.

\subsection{Piscina cubierta climatizada municipal de Toro (Zamora)}

Edificio desarrollado en tres plantas: semisótano, planta baja y primera. En la planta baja, de $1.081 \mathrm{~m}^{2}$ de superficie, se halla el acceso al recinto de la piscina, vestidores, los servicios sanitarios y las oficinas.

El proyecto, realizado por el estudio Vier Arquitectos S.L., ha sido galardonado por la Junta de Castilla y León con el primer premio de la convocatoria de los Premios de Construcción Sostenible de Castilla y León (20052006). Las obras terminaron a finales de 2010.

Los muros de fachada del cuerpo de accesos, del vestidor y del recinto de la piscina (Figura 14) son de tapia de tierra estabilizada con cemento blanco, cal aérea y con el añadido de gravas. Muros de $60 \mathrm{~cm}$ de ancho, constituyen la piel del edificio y le confieren una acusada personalidad, retomando la tradición histórica de las construcciones de tierra de la comarca.

Los encofrados que la empresa Betão e Taipa Lda, responsable de las tapias, empleó en esta obra son similares a los utilizados en la bodega de Lanciego, utilizándose también el mismo sistema de apisonado.

\subsection{Cuatro viviendas unifamiliares aisladas en el Baix Empordà (Girona)}

\section{Tipología de las viviendas}

Se trata de edificaciones aisladas de una o dos alturas, construidas entre los años 2005 y 2009, algunas completamente de nueva planta, mientras otras son el resultado de la ampliación de masías tradicionales de la comarca del Baix Empordà (Girona). Los elementos resistentes de los forjados son de madera, con diferentes soluciones en los entrevigados; cañizo, tableros, etc, sobre los que se ha extendido un lecho de hormigón. Hay 
que destacar el singular protagonismo de la tapia, que acaba por imprimir una intensa personalidad a cada una de las viviendas. Han sido proyectadas y dirigidas por Auquer Prats Arquitecturas S.L.

\section{Los muros de tapia}

Se construyen sobre zócalos de ladrillo o mampostería, realizados con tierra estabilizada con un porcentaje de 5 ó $6 \%$ de cemento, y con correcciones granulométricas. En los paramentos se visualiza la propia tierra apisonada sin ningún revestimiento ni tratamiento posterior, tanto en los paramentos interiores cuanto en los exteriores.

En todos los ejemplos que reseñamos se han efectuado algunos de los ensayos de laboratorio de identificación de tierras descritos.

\subsubsection{Vivienda en Mont-ras}

Vivienda (Figura 15) de una sola planta de $405 \mathrm{~m}^{2}$ de superficie, construida con muros portantes de tapia de $60 \mathrm{~cm}$ de ancho levantados sobre un zócalo de ladrillo, fábrica de ladrillo cerámico y forjados de madera.

Se empleó un tapial semejante al tradicional. El apisonado de la tierra se realizó manualmente, trabajo éste a cargo de Antonio Herrera, de la empresa Construccions Paltoni.

\subsubsection{Vivienda en Fontanilles}

Se trata de una vivienda de $400 \mathrm{~m}^{2}$ de nueva construcción de una sola planta, con un cuerpo central que cuenta con una planta superior.

La tapia está presente sobre todo en los muros de ordenación de los espacios exteriores de la parcela, y en el cuerpo de la atractiva chimenea, visible desde el exterior de la vivienda. Los muros tienen un ancho de $45 \mathrm{~cm}$.

En la construcción de los muros del jardín (Figura 16), se empleó un compactador neumático y encofrados metálicos; en la chimenea el apisonado fue manual y el tapial tradicional de madera. La empresa encargada de realizarlos fue la constructora Xedex S.L. y el tapiador Josep Canal.

\subsubsection{Vivienda en Rupià}

Inmueble de nueva construcción, de 400 m² de superficie (Figura 17). Es de una planta, con un cuerpo central que cuenta con un nivel superior, construido con muros de tapia, de 45 y $60 \mathrm{~cm}$ de espesor, ladrillo cerámico y adobe. Los dos primeros soportan las cargas de los forjados. Junto a la edificación principal se ha realizado un estudio de 70 $\mathrm{m}^{2}$ íntegramente con muros de tapia, cubier- ta de bóveda de ladrillo y terraza plana sobre estructura de madera.

Se ha empleado un tapial del tipo tradicional y el apisonado lo realizó manualmente la empresa Construïm el Compluvium S.L.

\subsubsection{Vivienda unifamiliar en Llabià (Girona)}

Edificación de $370 \mathrm{~m}^{2}$ desarrollados en dos plantas. Realizada con muros de 25 y $50 \mathrm{~cm}$ de espesor de tapia de tierra estabilizada con un $6 \%$ de cemento blanco, y con paredes de ladrillo cocido. Los dos tipos de
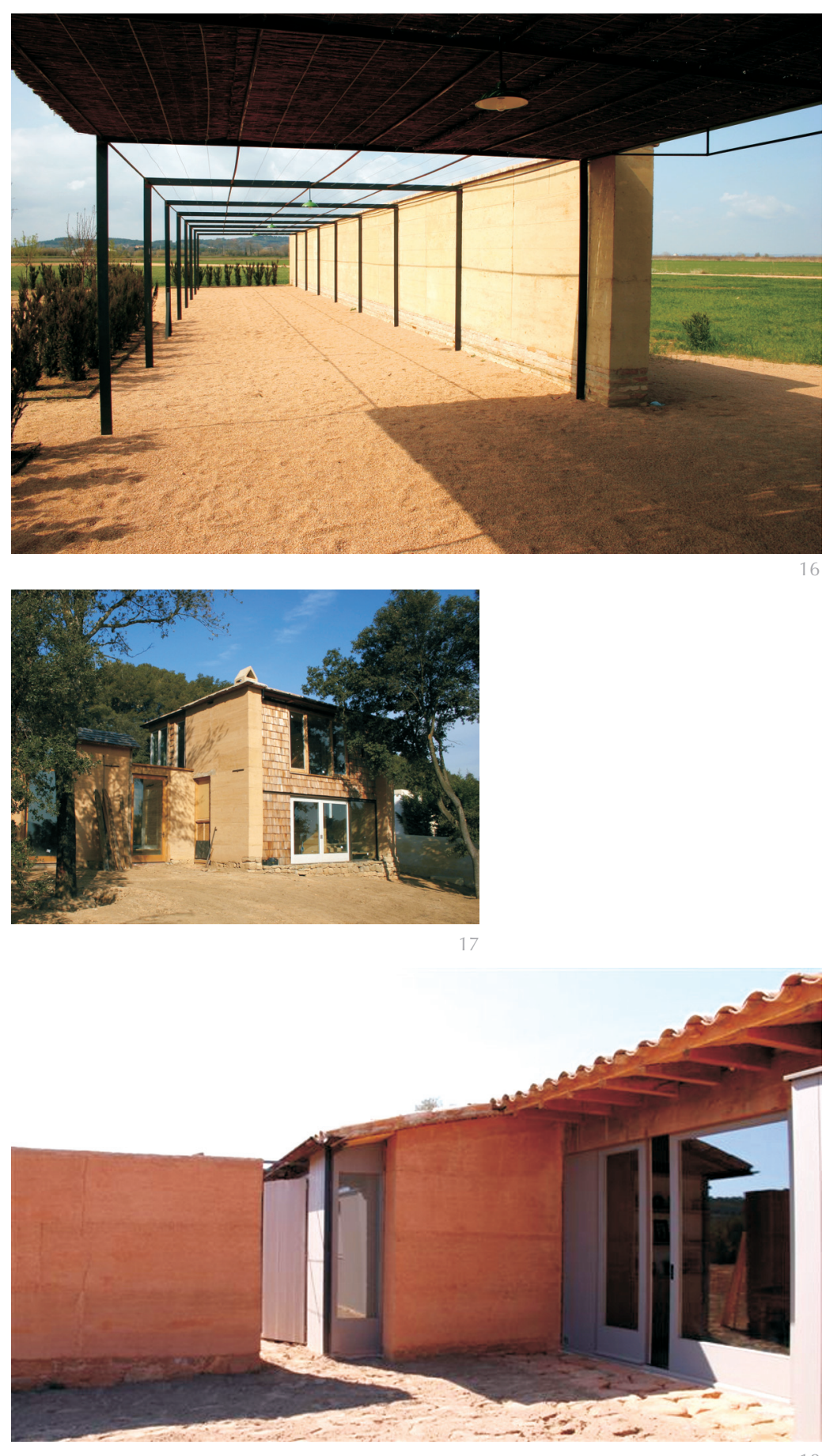

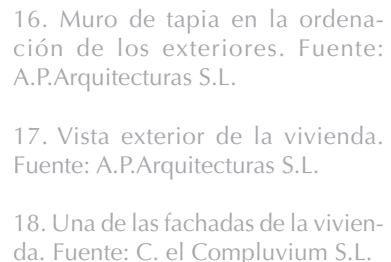

da. Fuente: C. el Compluvium S.L. 
19. Escuela infantil Santa Eulàlia de Ronçana. Acceso a la sala polivalente de la escuela. Fuente: G. Barbeta

20. La vivienda en fase de construcción. Fuente: G. Barbeta la envolvente de la sala de estar y de sostén de la estructura de la cubierta.
21. Paneles de tapia que conforman Fuente: S. Bestraten y E. Hormías

muros son los que sostienen los forjados de madera (Figura 18).

El tapial empleado ha sido el tradicional y el apisonado lo realizó manualmente la empresa Construïm el Compluvium S.L.

\subsection{Escuela infantil en Santa Eulàlia de Ronçana (Barcelona)}

Escuela para niños de 0 a 3 años finalizada en el año 2010, construida con bloques de tierra comprimida (BTC) y tapia. La mayor parte de los muros de la edificación es de BTC, así como las 6 cúpulas de más de 6 metros de diámetro que cubren las aulas. La
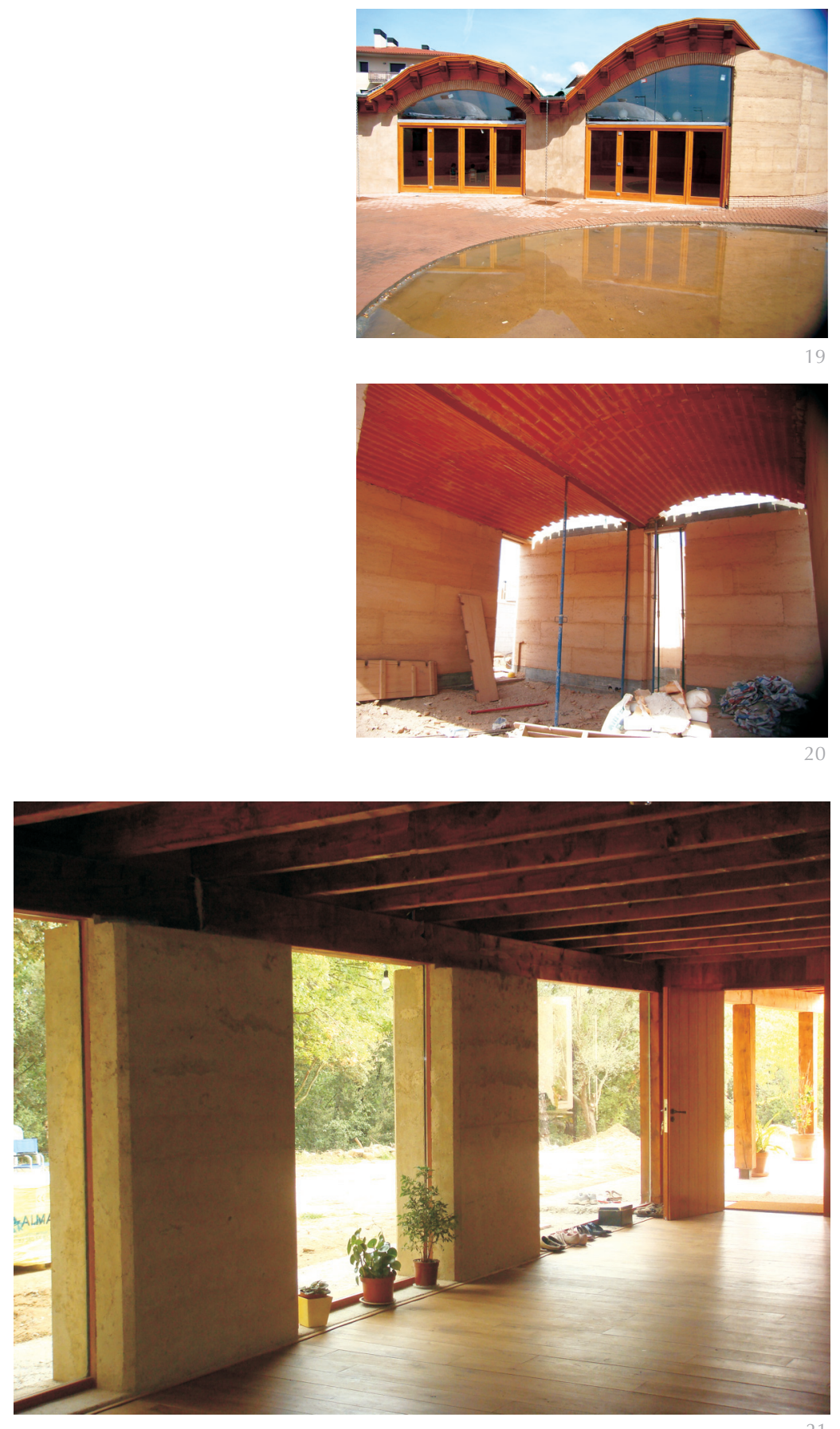

sala polivalente y el comedor (Figura 19), de una superficie de $70 \mathrm{~m}^{2}$, han sido construidos con muros de tapia de trazado curvo de $40 \mathrm{~cm}$ de espesor, con misión portante y de cerramiento. Los arquitectos responsables del proyecto han sido Gabriel Barbeta, Esteban Navarrete, Laura Barberá y Jordi Caminero.

Con objeto de reducir la considerable retracción de la tierra, observada en las pruebas de laboratorio, se ha incorporado fibras de madera así como perlita expandida para mejorar el aislamiento térmico, y cemento blanco como estabilizante. Los paramentos exteriores se protegerán con resina de silicona, y con la aplicación de silicato de potasio los interiores, para mejorar su respuesta a la acción del agua y a la erosión mecánica.

El encofrado se realizó con tablero contrachapado de pino adaptado a la curvatura, con un armazón de madera. El apisonado, fue realizado manualmente por la empresa Construïm el Compluvium S.L.

\subsection{Vivienda en la ciudad de Zaragoza}

Vivienda en construcción de planta baja y sótano, de $300 \mathrm{~m}^{2}$ de superficie, levantada con muros de tapia de tierra de $50 \mathrm{~cm}$ de espesor (Figura 20). Diseñada por los arquitectos Gabriel Barbeta, Sandra Bestraten y Emili Hormías.

Los muros se han realizado con tierra estabilizada con cemento y con correcciones granulométricas. Los paramentos exteriores se hidrofugarán con la aplicación de resina de silicona.

El encofrado empleado ha sido el tradicional de madera, apisonando la tierra manualmente. El responsable de las tapias del cercado del solar, levantadas en 2004, ha sido el tapiador Javier Capapé. Los muros de la vivienda fueron levantados por la empresa Construïm el Compluvium S.L.

\subsection{Casa rural en L'Esparra (Girona)}

Se trata de la rehabilitación de una casa tradicional en L'Esparra, aldea del término municipal de Riudarenes, proyectada por los arquitectos Sandra Bestraten y Emili Hormías. Concebida con criterios bioclimáticos, se desarrolla en semisótano, planta baja y altillo, con una superficie construida de $472,35 \mathrm{~m}^{2}$. La obra se terminó en el año 2007.

La antigua edificación, levantada con muros de mampostería, fue rehabilitada en su totalidad y ampliada para convertirla en casa rural con la adición en la fachada de un cuerpo que funciona como acceso y sala 


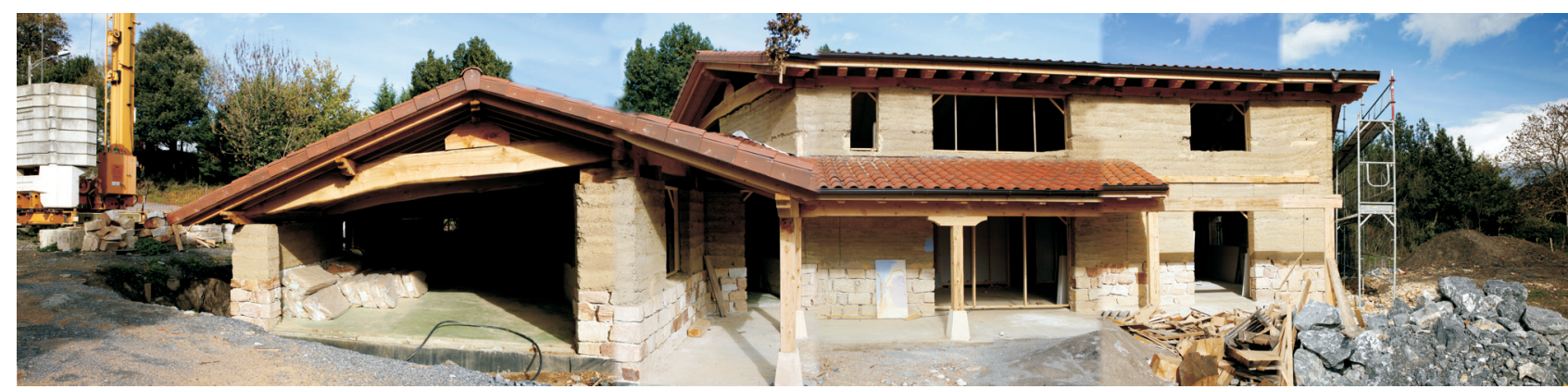

de estar y como terraza sustentada por pilares de madera. En la parte cerrada, muros de tapia de $40 \mathrm{~cm}$ de espesor sustentan la cubierta de estructura de madera (Figura 21). Un muro de tapia de $20 \mathrm{~cm}$ hace la función de compartimentación en el altillo.

La tierra empleada fue la del lugar, mezclándola a partes iguales con tierras arcillosas y con la adición de cemento blanco en un porcentaje del $10 \%$.

El encofrado empleado ha sido de tableros fenólicos con juntas de retracción de aluminio con apisonado mediante un pisón neumático. El responsable de las tapias ha sido el tapiador Josep Canal.

\subsection{Vivienda en Aramaiona (Álava)}

Vivienda en construcción de dos plantas de $170 \mathrm{~m}^{2}$, realizada con muros portantes de tapia de $60 \mathrm{~cm}$ de espesor en la planta baja y de $45 \mathrm{~cm}$ en la superior, con cubierta de teja a dos vertientes (Figura 22). Ha sido proyectada por los arquitectos Amaia Agiriano y Ekaitz Uribe del estudio Oreka Arkitektura.

A la tierra se le efectuaron correcciones granulométricas y se estabilizó con cemento blanco en un $10 \%$, según aconsejaron los resultados de las pruebas del laboratorio. Los paramentos verticales han sido revestidos con mortero preparados de cal.

Los encofrados se montaron corridos, empleándose tableros fenólicos con marco metálico sujetos con varillas envainadas, realizándose el apisonado con martillo eléctrico de la casa Bosch, modelo GSH-27, con una cabeza de $20 \times 20 \mathrm{~cm}$. El responsable de las tapias fue losu Jauregui Sarasola de la empresa Bioetxe S.L.

\section{CONCLUSIONES}

Mientras que en los países industrializados la construcción con tierra apisonada bajo los parámetros actuales se inicia a principios de los años ochenta del pasado siglo, en España habremos de esperar hasta mediados de los años 90 para ver surgir las primeras realizaciones con la construcción del teatro de Balaguer (18) o el conjunto de viviendas bioclimáticas de Amayuelas (19) y algunas pocas experiencias de autoconstrucción.

Es con la toma de conciencia por el medio ambiente de un cada vez más amplio sector de la población que se da el impulso a la construcción con tierra y surgen un número significativo de realizaciones. Pensamos que aunque es evidente el considerable desfase en relación a otros países industrializados, este se reducirá en los próximos años, pues el impulso que está tomando en España, al compás de la toma de conciencia social medioambiental, es imparable. Cuesta pensar que este país con su milenaria tradición en construcción con tierra pueda quedarse, por mucho tiempo, a la zaga de los países vecinos.

La tapia ha sido de las técnicas de puesta en obra de la tierra cruda la que ha atraído la mayor atención por parte de arquitectos y constructores europeos y también la que ha experimentado mayores innovaciones técnicas con la introducción de los encofrados industriales y el apisonado mecánico. Ya a principios de los años ochenta, en Francia el constructor Nicolas Meunier realiza paneles de tapia fabricados a pié de obra, y $\mathrm{M}$. Rauch (20) en taller, se adapta maquinaria de obras públicas para la mezcla y elevación de las tierras, se aplican tierras por proyección mecánica, entre otras innovaciones, que, aunque permiten abordar la construcción con tierra con planteamientos constructivos contemporáneos y mejoran las perspectivas de su competividad económica, todavía no logran que la construcción con tapia no se limite a una nueva arquitectura de lujo. Será, por tanto, necesario reinventar este modo de construir y profundizar en su evolución para adaptarlo a los actuales criterios de producción y a las exigencias normativas futuras, aunque para ello haya que alejarse de ciertos planteamientos nostálgicos que reivindican la tapia tradicional como sistema constructivo válido en la actualidad. Porque evolucionar en una técnica no significa necesariamente olvidar la tradición sino superarla. 


\section{BIBLIOGRAFÍA}

(1) Font, F.; Hidalgo, P.: El tapial. Una Tècnica constructiva mil.lenària. Colegio de Aparejadores y A.A.T.T. Castellón, 1990.

(2) Dethier, J.: Architectures de terre, pp.169-173, Centre Pompidou, París, 1986.

(3) Rauch, M.; Kapfinger, O.: Rammed Earth. Ed. Birhäuser, Basel, 2001.

(4) Minke, G.: Manual de construcción en tierra: la tierra como material de construcción y su aplicación en la arquitectura actual. Nordan-Comunidad, Montevideo, 2001.

(5) UNE 41410:2008. Bloques de tierra comprimida para muros y tabiques. Definiciones, especificaciones y métodos de ensayo. AENOR, Madrid, 2008.

(6) Font, F.; Hidalgo, P.: El tapial. Arquitecturas de Tapia. Colegio de Aparejadores y A.A.T.T. Castellón, 2009

(7) Barbeta, G.: Mejora de la tierra estabilizada en el desarrollo de una arquitectura sostenible hacia el siglo XXI. Tesis doctoral. www.tdr.cesca.es/TESIS_UPC/AVAILABLE/TDX-1105102-161519//02TESI1. pdf

(8) Houben, H.; Guillaud, H.: Traité de construction en terre, pp. 116-117, CRATerre-EAG, Parenthèses, Marsella, 1989.

(9) Doat, P.; Hays, A.; Houben, H.; Matuk,S.; y Vitoux, F.: CRATerre. Construire en terre. Éditions alternatives, Paris, 1979.

(10) Walker, P.; Keable, M.; Maniatidis, J. R.: Rammed earth. Desing and construction guidelines. BRE Bookshop, Reino Unido, 2005.

(11) P.I.R.T. 70 Prescripciones del Instituto Eduardo Torroja. Obras de fábrica. p. 121, Madrid, 1971.

(12) Norma UNE 41410. Ob. Cit., p.12, 2008.

(13) Valverde, I.; Ontiveros, E.; Sebastián, E.: "El tapial de las murallas de Granada". Revista de Edificación, $\mathrm{n}^{\circ} 26$ (1997).

(14) Barbeta, G.: Ob. Cit.

(15) Maldonado, L.; Castilla, F. J.; Vela F.: "La técnica del tapial en la Comunidad Autónoma de Madrid. Aplicación de nuevos materiales para la consolidación de muros de tapia". Informes de la Construcción, Vol. 49 n 452 (1997). Instituto Eduardo Torroja, Madrid.

(16) Rauch, M.: "Construir con barro apisonado". DETAIL: Revista de Arquitectura y Detalles Constructivos, Año 4, nº 3 (2004).

(17) Rauch, M.; Kapfinger, O.: Ob. Cit.

(18) Font, F.; Hidalgo, P. O.: Ob. Cit., pp.166.

(19) Jimenez, M. C.; Cañas, I.: "Earth building in Spain" Construction and Building Materials $\mathrm{n}^{\circ} 20$, 679-690 (2006), pp. 684

(20) Obra Colectiva. Terra Incognita. pp. 88-89, Argumentum/Culture Lab Editions, Portugal/Bélgica, 2009. 